\title{
Perception of Nurses and Physicians about Importance of Their Collaboration in the Work
}

\author{
Lamiaa R. Goda1; Sanaa M. Aref 2; Awatef M. Abdel-Razek3
}

1 B.Sc. Faculty of Nursing-Minia University;

2 Assisst Professor of Nursing Administration Department, Faculty of Nursing, Minia University, 3 Professor of Community Health Nursing Department, Faculty of Nursing, Minia University

\begin{abstract}
Background: Nursing and medicine are two professions, which have many roles that interact with their responsibilities. Collaboration has been promoting as one of the best approaches for healthcare systems to adopt when trying to progress the outcomes Aim: assess the perception of nurses and physicians about the importance of collaboration in the work. Methods: A descriptive research design was used. Setting: The study was conducted at Beni-Suef University Hospital in four critical care units ICU,CCU,PCU,NSCU and medical, surgical department. subjects: A convenience sample was used. One hundred of nurses and fifty of physicians working at Beni-Suef University Hospital were included in the current study. Tool: included two parts part one personal characteristics questionnaire and part two collaboration perception scales for physicians and nurses. Results: the current study revealed that all of studied physicians had suboptimal perceptions regarding nurse/physician collaboration, and more than three quarters of nurses had suboptimal perceptions regarding nurse/physician collaboration. There was a highly significant relation between the mean score of collaboration perception scale for physicians and collaboration perception scale for nurses at $\mathrm{p} \leq 0.01$. Conclusion: Most nurses and all physicians have suboptimal perceptions regarding nurse/physician collaboration. Moreover, the mean score of collaboration perception scale for nurses and physicians has a significant relationship with gender, years of experience and all working place except for surgical department. Recommendations: encouraging inter-professional collaboration in healthcare institutions by managers and administration. Establishing a base for inter-professional collaboration between all healthcare team members in nursing and medical schools. Clearing job description for all categories of nurses and physicians.
\end{abstract}

Keywords: Collaboration, Nurses, Physicians.

\section{Introduction}

Healthcare delivery system today challenges all of healthcare provider's contributors to provide patients with that are efficient, effective, saving time and cost for both patients and healthcare delivery systems, and also to be easily accessible. Nurse/physician collaboration is defined as actions related to information sharing about patients, contributing in decision-making related to patient care, and providing complete patient-centered perspective care. Three key factors form nurse/physician collaboration; joint participation in the cure/care decision-making process, sharing information of the patient, and degree of cooperation (1) .

Collaboration has been considering as one of the best approaches for healthcare systems to adopt when trying to progress the outcomes. Collaboration also improves the efficiency and effectiveness of healthcare practice, and develops patient's outcomes. In other words, teamwork's effective collaborative is designed for team members to understand and share the skills, responsibilities, trust, knowledge, and functions of each member of the team for the treatment decisions and improving patient's outcomes (2). Nursing and medicine are two professions, which have many roles that interact with confused responsibilities in addition to areas of functions. Physicians are responsible for the patients and are legally accountable for their treatment (3).

Moreover, nurses carry out specific parts of the treatment, which requested to be provided because they have sufficient experiences and explanations. Temporarily, physicians rely on nurses on reporting any changes that might happen in patients' conditions, that's include any adverse reactions from the treatment that they might observe during caring for patients (4). Successful collaboration between physicians and both registered nurses and nursing practitioners has been shown to reduce rates of both morbidity and mortality, decrease the cost of healthcare, and medical errors. The nursing workforce is expected to decrease by $20 \%$ by 2020 , which might put the profession in a dangerous shortage. Nurse/physician collaboration has been evident to improve professional nurses' job satisfaction and is considered an elevated priority for nurses' retention (5).

A successful climate for patient's safety is being considered as the primary and one of the major principles in organizations concerned with healthcare. This is because every process performed with a member of healthcare caries a potential risks and possible problems associated with its use in actual healthcare practice (6). Nursing and medicine are two entitles that have contribution in healthcare management and in market place. Hospitals improve compensation and be market share when healthy interprofessional physicians and nurses relationships are accomplished. Such relationships in turn reflect on patients' quality of care (1).

\section{Significance of the study}

The researcher observed during working at BeniSuef University Hospital that there were some conflicts between nurses and physicians due to poor communication and lack of collaboration. This miscommunication had

\section{Lamiaa R., et al}


affected patients' care outcome, which may affect the total hospital productivity and quality of care. It also leads to nurses' job dissatisfaction, which lead to job burnout and turnover (7).

So it is important to assess nurses and physician perception about their collaboration at work.

\section{Aim of the study:}

[1]. Assess nurses' perception about the importance of nurse/physician collaboration in work at Beni-Suef University Hospital

[2]. Assess physicians' perception about the importance of nurse/physician collaboration in work at BeniSuef University Hospital.

Research questions: To fulfill the aim of the study, the following research questions were formulated:

- Is there a positive collaboration between nurses and physicians in work at Beni-Suef University Hospital?

- Is there a relation between personal characteristics data and the level of collaboration between nurses and physicians in work at Beni-Suef University Hospital?

\section{Subjects \& methods \\ Research Design: A descriptive research design} was utilized in the current study.

Setting: The study was conducted at Beni-Suef University Hospital located in Beni-Suef city, which developed in 1985 . The capacity of the hospital is 380 beds in all departments and the current study was conducted at four critical care units (icu,ccu,pcu,nscu) plus medical and surgical departments.

Subjects: A convenience sample was used in the current study. All nurses and physicians in four critical care units, medical and surgical departments at Beni-Suef University Hospital were included in the current study with no exclusion criteria.

Tool of data collection: to achieve the aim of the study, data collected by the following tools:

\section{Tool (1): This included two parts}

Part-1 Physicians' personal characteristics data Questionnaire: structure interview sheet was designed by the researcher after reviewing the related literatures. It included 6 questions as age, gender, level of education, employment status, department and years of experience.

Part-2 Collaborative Practice Scale for Physicians (CPS): adopted from Weiss and Davis1985 (8) to assess collaborative practice of physicians and assess perception of physicians about collaboration with nurses at work. The CPS for physicians consists of 10 items. It is a 6-point Likert scale "never $=1$," "rarely=2," "sometimes $=3$," "usually $=4$ " "mostly $=5$," and "always=6". The minimum and maximum values range from 10 to 60 .
Scoring for Collaborative Practice Scale for Physicians:

\begin{tabular}{|l|l|}
\hline Physicians' Perception & Score \\
\hline Suboptimal Perception & $10-45$ \\
\hline Optimal Perception & $46-60$ \\
\hline
\end{tabular}

\section{Tool (2): This included two parts}

Part 1- Nurses' personal characteristics data Questionnaire: Structure interview sheet was designed by the researcher after reviewing the related literatures. It included 6 questions as age, gender, level of education, employment status, department and years of experience.

Part-2 Collaborative Practice Scale for Nurses (CPS): adopted from Weiss and Davis1985(8) to assess collaborative practice of nurses and assess perception of nurses about collaboration with physicians in work. The CPS for nurses consists of 9 items.

Scoring System It is a 6-point Likert scale.

(Never=1 "rarely=2," "sometimes $=3$," "usually=4" "mostly=5," and "always=6)

\section{Scoring for Collaborative Practice Scale for Nurses:}

\begin{tabular}{|l|l|}
\hline Nurses' Perception & Score \\
\hline Suboptimal Perception & $9-29$ \\
\hline Optimal Perception & $30-36$ \\
\hline
\end{tabular}

\section{Validity and Reliability}

The tools were tested and evaluated for their content validity, and reliability. Content validity is tested by three experts, one expert in community health nursing and two experts in nursing administration. They were from different academic categories, i.e., professor and assistant professor.

\section{Reliability}

The reliability of the data collection tools was assessed through measuring their internal consistency by Cronbach's Alpha Coefficient test. It was 0.787 for CPS for Nurses and 0.801 for CPS for physicians.

\section{Field work}

The actual fieldwork for the process of data collection has consumed six months. Nurses and physicians included in the study were asked to give an oral agreement prior to participating in the study. This agreement was after the researcher explained the nature and aim of the study, they were reassured that information collected was used for the research purposes only.

The researcher sat with each participant and asked the questionnaire. The average time of data collection was about 20 to 30 minutes for each participant.

Pilot Study:

A pilot study was conducted before starting the current study to investigate the visibility of data collection tools, their content validity, clarity of the items and the time required to fill them. It included 10 nurses and 5 physicians, which represented $10 \%$ from total sample size and was 
excluded from the total sample size. No comments regarding the difficulty of terminology, questions structure or items clarity were reported by the study sample.

\section{Ethical Considerations:}

The ethical research considerations in this study included the following items:

A written initial approval was obtained from the research ethical committee at the Faculty of Nursing, Minia University and Individual oral agreement was obtained from each participant after explaining the nature and purposes of the study. And the anonymity and confidentiality were also assured. The researcher cleared the aim of the study to participants. The researcher maintained on confidentiality of participants. Written consent was taken from the director of Beni-Suef University Hospital. An official permission to conduct the proposed study was issued from the Faculty of Nursing, Minia University to the Director of a Beni-Suef University Hospital requesting approval for conducting this study procedure

\section{Statistical Analysis}

The collected data were organized, analyzed using appropriate statistical significant tests. The data were collected and coded. Using the Computer Statistical Package for Social Science (SPSS), version 21, the statistical analysis of data was done. Data were presented using descriptive statistics in the form of frequencies and percentages. Chi square test was used to compare the frequencies in two groups.

\section{Results}

Table (1): Distribution of personal Characteristics of Physicians and Nurses in the Study

\begin{tabular}{|c|c|c|c|c|}
\hline \multirow[b]{2}{*}{ Personal Characteristics } & \multicolumn{2}{|l|}{ Physicians } & \multicolumn{2}{|l|}{ Nurses } \\
\hline & No. $(\mathrm{N}=50)$ & $\%$ & $\begin{array}{l}\text { No. } \\
(\mathrm{N}=100)\end{array}$ & $\%$ \\
\hline \multicolumn{5}{|l|}{ Sex } \\
\hline Male & 36 & 72.0 & 22 & 22.0 \\
\hline Female & 14 & 28.0 & 78 & 78.0 \\
\hline \multicolumn{5}{|l|}{ Age/ years } \\
\hline$\leq 30$ years & 24 & 48.0 & 30 & 30.0 \\
\hline$>30$ years & 26 & 52.0 & 70 & 70.0 \\
\hline Mean \pm SD & \multicolumn{2}{|c|}{$31 \pm 8.41$ year } & \multicolumn{2}{|c|}{$33 \pm 28.24$ year } \\
\hline Years of Experience & & & & \\
\hline$\leq 5$ years & 31 & 62.0 & 91 & 91.0 \\
\hline$>5$ years & 19 & 38.0 & 9 & 9.0 \\
\hline \multicolumn{5}{|l|}{ Employment status } \\
\hline Resident doctor/ Head nurse & 26 & 52.0 & 30 & 30.0 \\
\hline $\begin{array}{l}\text { University staff/ Nurses and nursing } \\
\text { assistants }\end{array}$ & 24 & 48.0 & 70 & 70.0 \\
\hline \multicolumn{5}{|l|}{ Level of Education } \\
\hline Bachelor degree/ Institute and diploma nurse & 25 & 50.0 & 48 & 48.0 \\
\hline $\begin{array}{l}\text { Post graduate degrees/ Bachelor degree } \\
\text { nurses }\end{array}$ & 25 & 50.0 & 52 & 52.0 \\
\hline \multicolumn{5}{|l|}{ Department } \\
\hline ICU & 7 & 14.0 & 19 & 19.0 \\
\hline $\mathrm{CCU}$ & 10 & 20.0 & 10 & 10.0 \\
\hline $\mathrm{PCU}$ & 5 & 10.0 & 17 & 17.0 \\
\hline $\mathrm{NSCU}$ & 5 & 10.0 & 10 & 10.0 \\
\hline Medical department & 15 & 30.0 & 25 & 25.0 \\
\hline Surgical department & 8 & 16.0 & 19 & 19.0 \\
\hline
\end{tabular}

Table (1) showed that nearly three quarter $(72 \%)$ of studied physicians were males and more than half $(52 \%)$ were aged more than thirty years with mean age $31 \pm 8.41$ year. Regarding years of experiences $62 \%$ of the studied physicians had less than five years of experience and $52 \%$ of them were residents.

Also, table (1) revealed that more than three quarters $(78 \%)$ of studied nurses were females and more than two thirds $(70 \%)$ of them aged more than thirty years with mean age $33 \pm 28.24$ year. Regarding to years of experience $91 \%$ of them had less than five years and $70 \%$ of them were beside nurses and nursing assistants. Regarding education and working department, $52 \%$ of them had a bachelor degree in nursing.

\section{Lamiaa R., et al}




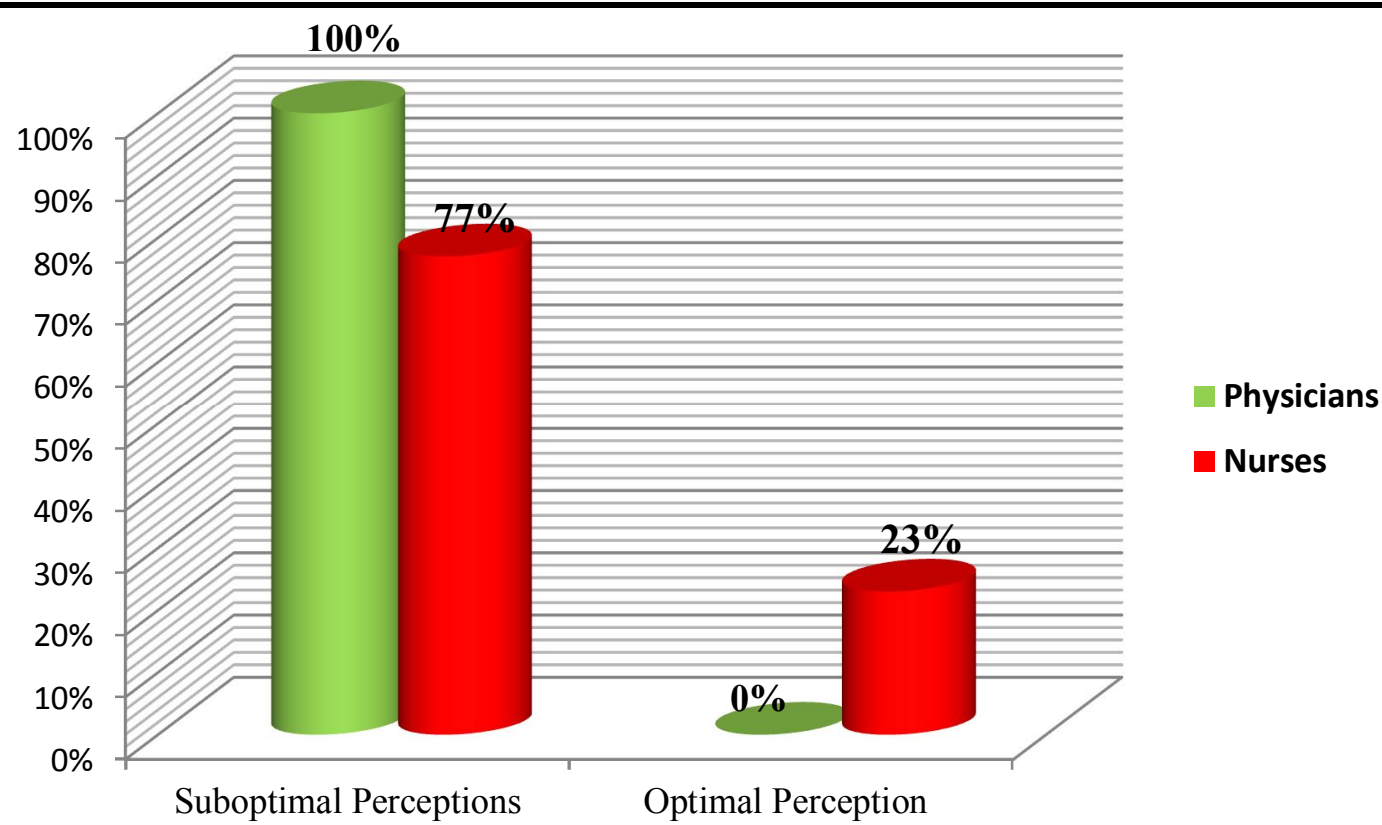

Figure (1): Percentage distribution levels of perception regarding nurse/physician collaboration among studied sample

Figure (1), illustrated that, all studied physicians $(100.0 \%)$ vs $77 \%$ of studied nurses had suboptimal perceptions regarding nurse/physician collaboration and
$23 \%$ of nurses had optimal perceptions vs. no one of physician.

Table (2): Relationship between demographic Characteristics and levels of Collaboration Perception for Nurses in the Study. $(\mathbf{n}=100)$.

\begin{tabular}{|c|c|c|c|c|c|c|}
\hline \multirow{3}{*}{$\begin{array}{l}\text { Demographic } \\
\text { characteristic }\end{array}$} & \multicolumn{4}{|c|}{ Collaboration perception } & \multirow{3}{*}{$\mathrm{X} 2$} & \multirow{3}{*}{ p-value } \\
\hline & \multicolumn{2}{|c|}{ Suboptimal } & \multicolumn{2}{|c|}{ Optimal } & & \\
\hline & No. & $\%$ & No. & $\%$ & & \\
\hline Sex & & & & & & \\
\hline Male & 15 & 15.0 & 7 & 7.0 & 1.238 & 0.267 \\
\hline Female & 62 & 62.0 & 16 & 16.0 & & \\
\hline Age & & & & & & \\
\hline$\leq 30$ years & 19 & 19.0 & 11 & 11.0 & 4.520 & $0.034^{*}$ \\
\hline$>30$ years & 58 & 58.0 & 12 & 12.0 & & \\
\hline Years of Experience & & & & & $\mathrm{F}$ & \\
\hline$\leq 5$ years & 70 & 70.0 & 21 & 21.0 & 0.003 & 0.954 \\
\hline$>5$ years & 7 & 7.0 & 2 & 2.0 & & \\
\hline Employment status & & & & & & \\
\hline Head nurse & 23 & 23.0 & 7 & 7.0 & 0.003 & 0.959 \\
\hline Nurses \& assistances & 54 & 54.0 & 16 & 16.0 & & \\
\hline Education levels & & & & & & \\
\hline Institute and diploma & 39 & 39.0 & 9 & 9.0 & 0.941 & 0.332 \\
\hline Bachelor degree & 38 & 38.0 & 14 & 14.0 & & \\
\hline Department & & & & & $\bar{F}$ & \\
\hline & 13 & 13.0 & 6 & 6.0 & 8.462 & $0.033^{*}$ \\
\hline $\mathrm{CCU}$ & 5 & 5.0 & 5 & 5.0 & & \\
\hline PCU & 13 & 13.0 & 4 & 4.0 & & \\
\hline NSCU & 8 & 8.0 & 2 & 2.0 & & \\
\hline Medical department & 20 & 20.0 & 5 & 5.0 & & \\
\hline Surgical department & 18 & 18.0 & 1 & 1.0 & & \\
\hline
\end{tabular}


* Significant at $\mathrm{p}<0.05$

Table (2) Showed that, $58 \%$ of nurses aged more than 30 years and $20 \%$ of nurses had suboptimal collaboration perception working in medical department with statistical significant differences which $\mathrm{p} \leq 0.034$
\& .033 respectively. At the same times, the table presented that there no significant relationship as regard sex, years of experience, employment status and education level of studied nurses and collaboration perception level of nurses.

Table (3): Mean score of personal characteristics and Collaboration Perception level among subjects in the study.

\begin{tabular}{|c|c|c|c|c|}
\hline \multirow{2}{*}{ personal Characteristic } & \multicolumn{2}{|c|}{ Physicians $(\mathrm{n}=50)$} & \multicolumn{2}{|c|}{ Nurses $(n=100)$} \\
\hline & $\mathrm{N}$ & Mean \pm SD & $\mathrm{N}$ & Mean \pm SD \\
\hline \multicolumn{5}{|l|}{ Sex } \\
\hline Male & 36 & $28.4 \pm 5.5$ & 22 & $26.1 \pm 7.4$ \\
\hline Female & 14 & $28.9 \pm 4.9$ & 78 & $25.3 \pm 6.3$ \\
\hline $\mathrm{t}(\mathrm{P}-$ value $)$ & \multicolumn{2}{|c|}{$0.068(.769)$} & \multicolumn{2}{|c|}{$0.252(.617)$} \\
\hline \multicolumn{5}{|l|}{ Age/ years } \\
\hline$\leq 30$ years & 24 & $29.3 \pm 6.4$ & 30 & $27.8 \pm 6.3$ \\
\hline$>30$ years & 26 & $27.9 \pm 4.1$ & 70 & $24.5 \pm 6.4$ \\
\hline $\mathrm{t}(\mathrm{P}-$ value $)$ & \multicolumn{2}{|c|}{$0.817(.371)$} & \multicolumn{2}{|c|}{$5.694\left(.019^{*}\right)$} \\
\hline \multicolumn{5}{|l|}{ Years of Exp } \\
\hline$\leq 5$ years & 31 & $27.3 \pm 4.2$ & 91 & $25.7 \pm 6.2$ \\
\hline$>5$ years & 19 & $30.6 \pm 6.3$ & 9 & $22.8 \pm 9.5$ \\
\hline $\mathrm{t}(\mathrm{P}-$ value $)$ & \multicolumn{2}{|c|}{$5.122\left(.028^{*}\right)$} & \multicolumn{2}{|c|}{$1.687(.197)$} \\
\hline \multicolumn{5}{|l|}{ Employment status } \\
\hline Resident doctor/ Head nurse & 26 & $27.5 \pm 4.3$ & 30 & $26.5 \pm 5.4$ \\
\hline $\begin{array}{l}\text { University staff/ Nurses and } \\
\text { nursing assistants }\end{array}$ & 24 & $29.7 \pm 6.1$ & 70 & $25.1 \pm 6.9$ \\
\hline $\mathrm{F}(\mathrm{P}-$ value $)$ & \multicolumn{2}{|c|}{$2.278(.138)$} & \multicolumn{2}{|c|}{$1.063(.305)$} \\
\hline \multicolumn{5}{|l|}{ Level of Education } \\
\hline $\begin{array}{l}\text { Bachelor degree/ Institute and } \\
\text { diploma nurse }\end{array}$ & 25 & $27.8 \pm 4.3$ & 48 & $24.6 \pm 6.6$ \\
\hline $\begin{array}{l}\text { Post graduate degrees/ Bachelor } \\
\text { degree nurses }\end{array}$ & 25 & $28.3 \pm 6.0$ & 52 & $26.3 \pm 6.4$ \\
\hline $\mathrm{F}(\mathrm{P}-$ value $)$ & \multicolumn{2}{|c|}{$1.074(.305)$} & \multicolumn{2}{|c|}{$1.708(.194)$} \\
\hline \multicolumn{5}{|l|}{ Working place } \\
\hline ICU & 7 & $29.6 \pm 3.9$ & 19 & $26.2 \pm 7.9$ \\
\hline $\mathrm{CCU}$ & 10 & $31.2 \pm 6.1$ & 10 & $30.2 \pm 3.4$ \\
\hline PCU & 5 & $27.6 \pm 5.5$ & 17 & $25.4 \pm 6.6$ \\
\hline NSCU & 5 & $24.6 \pm 6.4$ & 10 & $25.6 \pm 3.7$ \\
\hline Medical department & 15 & $29.3 \pm 4.6$ & 25 & $24.3 \pm 7.2$ \\
\hline Surgical department & 8 & $25.9 \pm 4.8$ & 19 & $23.8 \pm 5.9$ \\
\hline $\mathrm{F}(\mathrm{P}-$ value $)$ & \multicolumn{2}{|c|}{$1.712(.152)$} & \multicolumn{2}{|c|}{$1.554(.181)$} \\
\hline
\end{tabular}

\section{* Significant at $\mathrm{P} \leq 0.05$}

Table (3) Revealed a significant relation between mean score collaboration perception of physicians who had five years of experience or less and physicians who had more than five years of experience at $\mathrm{P} \leq 0.05$. In the same

\section{Discussion}

The collaboration has been advocated as one of the best strategies for health care systems to adopt when trying to improve outcomes collaboration also enhances the P a g e $\mid \mathbf{1 3}$ table no significant relation between mean collaboration perception of nurses and demographic characteristics except nurses age which $\mathrm{P} \leq 0.05$.

effectiveness and efficiency of practice, and also improves patient outcomes, In other words, effective collaborative teamwork is designed for team members to share and understand the responsibilities, skills, knowledge, trust and 
functions of every member of the team for treatment decisions and patient outcomes. The present study has been conducted to assess perceptions of nurses and physicians about the importance of their collaboration in the work.

The present study was carried out on fifty physicians and one hundred nurses, which revealed that almost three quarters of the studied physicians, were males. The curent results study were similar to the results from Siedlecki, Hixson,(2015)(9) who studied the relationships between nurses and physicians who reported that most of their physicians were males.

Regarding studied nurses personal characteristics, more than three quadrants of studied nurses were females. This may be due to the fact that females are still the main gender in the nursing profession. This finding is consistent with Sayed, (2011)(10) who studied the attitude of nurses and physicians regarding collaboration in Mansoura University and revealed that most of studied nurses were females. Siedlecki, Hixson,(2015)(9) also reported that most of their nursing sample was females.

The current study revealed that, all studied physicians and more than three quarters of studied nurses reported suboptimal perceptions regarding nurse/physician collaboration. This may be due to the authoritarian nature of physicians in the healthcare setting and the power imposed by hospital administration to support physicians all the time.

In agreement with the current study, the study of Weller, Barrow, (2011)(11)who studied the interprofessional collaboration between junior physicians and nurses in healthcare setting and revealed the presence of some barriers that interfere with the completion of that collaboration process between them, some of the highlighted barriers were organizational problems due to hospital administration and limitations imposed over professional workplace relationships.

In addition, the study of Papathanassoglou, Karanikola (2012) (12)who studied the collaboration between nurses and physicians in intensive care units in Europe also revealed the presence of none co-operational relationship between nurses and physicians due to insufficient autonomy that resulted in moral distress among ICU nurses.

In disagreement with this result; the study of Hughes and Fitzpatrick, (2010) (5)who studied nurse/physician collaboration in acute care community health hospital and revealed a positive attitudes from both nurses and physicians toward collaboration. That disagreement could be due to the different cultures and different work setting, as in acute care facilities the collaboration is a must for the best interest of the patients care.

Moreover, Maxson, Dozois, (2011) (13) who found that enhancing nurse/physician collaboration in clinical decision-making was done through high-fidelity interdisciplinary simulation training, their implemented program reported to enhance the nurse/physician collaboration among both parts of the collaboration process which the researchers found to be insufficient and reported dissatisfactory before the implementation of the program.

Contradicted to this result, the study of Sollami, Caricati, (2015)(14) who conducted a meta-analysis investigation on nurse/physician collaboration and reported

P a g e $\mid \mathbf{1 4}$ that physicians scored higher in perception than nurses, while nurses had more positive attitudes regarding collaboration than physicians. This study results revealed that while physicians think that collaboration already exist, nurses still desiring more and more collaboration and they are more open to the idea of collaboration than physicians do. This opposition may be congruent with the current study with nurses' opinion, because they both had less perception regarding the nurse/physician collaboration.

Study done by Wen, Guan, (2017) (15) also supports the results of the current study. They investigated physicians' perceptions related to nurse/physician collaboration and concluded the considerable need for information regarding nurse/physician collaboration and the need to improve communication needs as well between nurses and physicians.

The current study presented that there is a significant relationship between physicians and nurses' collaboration perceptions mean scores for physicians and nurses and the working department . This could be due to the difference in working nature in different departments; some departments require more interaction and close relationship between healthcare staff members than others.

In disagreement with the current study results, the study of Asghari, Saadati, (2015) (16) who investigated the relationship between communication and collaboration between nurses and physicians in Neyshabur and reported no significant relationship between the different departments and collaboration among studied subjects. This disagreement could be related to different working standards in different healthcare establishments.

Regarding the relationship between levels of collaboration perception and gender, the current study revealed that a highly significant relationship between levels of collaboration perception for physicians and nurses as regard gender. The study of Asghari, (2015) (16) oppose this result, as they reported in their study that no significant relationship between gender and collaboration perception were found.

Regarding levels of collaboration perception and years of experience for physicians, the current study showed that, a highly significant relationship between levels of collaboration perception for physicians and nurses and their years of experience. The study of Sayed, (2011) (10) revealed a significant relationship between nurses and physicians' experiences and their nurse/physician collaboration perception.

However, in contradiction with the current study the study of Elsous, Radwan, (2017) (17) who studied nurses and physicians attitudes toward nurse/physician collaboration and reported that year of experience had no influence over subjects' collaboration perception. This contradiction between the two studies' results could be related to the different sample sizes.

\section{Conclusion}

Based on the results of the current study; it can be concluded that: more than three quarters of nurses and all physicians have suboptimal perceptions regarding nurse/physician collaboration. In addition, working place has a significant relationship with nurses and physicians perceptions regarding nurse/physician collaboration.

Lamiaa R., et al 
Moreover, the mean score of collaboration perception scale for nurses and physicians has a significant relationship with gender, years of experience and all working place except for surgical department.

\section{Recommendations}

Based on findings of the present study: the following are recommended:

- Encouraging inter-professional collaboration in healthcare institutions by managers and administrations.

- Giving rewards for well-established interprofessional collaboration between nurses and physicians.

- Providing training about importance of collaboration

- Establishing a base for inter-professional collaboration between all healthcare team members in nursing and medical schools.

- Increasing the understanding nurses and physicians complementary roles

- Clearing job description for all categories of nurses and physicians

\section{References}

[1]. Safaan SM, Ekhouly EA, Ibrahim RA. Collaboration among Nurses and Physician and its relation to patient satisfaction. International Journal of Current Research 2015;7(3).

[2]. Martin JS, Ummenhofer W, Manser T, Spirig R. Interprofessional collaboration among nurses and physicians: Making a difference in patient outcome. Swiss Medical Weekly 2010;140.

[3]. Arlene D. Physician-nurse collaboration inthe $21 \mathrm{st}$ century. Philadelphia 2005;22(5):774-6.

[4]. Ergün Y, Yildirim A. Attitude toward Physician/Nurse collaboration in intensive care unit. Copenhag-Denmark: Marmara University, Health Science Faculty; 2011.

[5]. Hughes BM, Fitzpatrick JJ. Nurse-physician collaboration in an acute care community hospital. J Interprof Care 2010;24(6):625-32.

[6]. Kramer M, Schmalenberg C. Securing "good" nurse/physician relationships. Nurs Manage 2003;34(7):34-8.

[7]. Nazarey M. A nursing shortage: Building organizational commitment among nurses:
Practitioner application. Journal of Healthcare Management 2001.

[8]. Weiss SJ, Davis HP. Validity and reliability of the collaborative practice scale. Journal of Nursing Research 1985;34(5):299-305.

[9]. Siedlecki SL, Hixson ED. Relationships Between Nurses and Physicians Matter. The Online Journal of Issues in Nursing 2015;20(3).

[10]. Karima A, Sayed EL, Wafaa FS. NursePhysician Collaboration; A Comparative Study of The Attitudes of Nurses and Physicians at Mansoura University Hospital. Life science Journal $2011 ; 8(2)$.

[11]. Weller JM, Barrow M, Gasquoine S. Interprofessional collaboration among junior doctors and nurses in the hospital setting. Medical education 2011;45(5):478-87.

[12]. Papathanassoglou ED, Karanikola MN, Kalafati M, Giannakopoulou M, Lemonidou C, Albarran JW. Professional autonomy, collaboration with physicians, and moral distress among European intensive care nurses. American Journal of Critical Care 2012; 21(2):e41-e52.

[13]. Maxson PM, Dozois EJ, Holubar SD, Wrobleski DM, Dube JAO, Klipfel JM, et al. Enhancing nurse and physician collaboration in clinical decision making through high-fidelity interdisciplinary simulation training. In: Mayo Clinic Proceedings: Elsevier; 2011. p. 31-6.

[14]. Sollami A, Caricati L, Sarli L. Nurse-physician collaboration: a meta-analytical investigation of survey scores. Journal of interprofessional care 2015;29(3):223-9.

[15]. Wen D, Guan P, Zhang X, Lei J. Physicians' perceptions of physician-nurse interactions and information needs in China. Informatics for Health and Social Care 2017:1-10.

[16]. Asghari A, Saadati SM, Ahmadpour S, Ghodsi A, Vaezi A. Communication and collaboration's nurse with physician from the perspective of hospitals nurse in Neyshabur City 2013. Sch. J. App. Med. Sci. 2015;3(9c):3335-41.

[17]. Elsous A, Radwan M, Mohsen S. Nurses and Physicians Attitudes toward Nurse-Physician Collaboration: A Survey from Gaza Strip, Palestine. Nursing Research and Practice; 2017. 